\title{
Modulatory effect of ascorbic acid on physiological responses of transported ostrich chicks
}

\begin{abstract}
Authors:
Minka N. Salka ${ }^{1}$

Ayo J. Olusegun ${ }^{2}$

Affiliations:

${ }^{1}$ College of Agriculture and Animal Science, Ahmadu Bello University, Nigeria

${ }^{2}$ Department of Physiology and Pharmacology, Ahmadu Bello University, Nigeria

Correspondence to:

Minka Salka

Email:

mnsalka@yahoo.com

Postal address:

Private Bag 2134, D.A.C. Ahmadu Bello University, Mando-Kaduna, Nigeria

\section{Dates:}

Received: 09 Dec. 2011 Accepted: 07 Mar. 2012

Published: 24 May 2012

How to cite this article: Salka, M.N. \& Olusegun, A.J., 2012, 'Modulatory effect of ascorbic acid on physiological responses of transported ostrich chicks', Onderstepoort Journal of Veterinary Research 79(1), Art. \#388, 7 pages. http:// dx.doi.org/10.4102/ojvr. v79i1. 388
\end{abstract}

The aims of this study were to determine the modulating role of ascorbic acid (AA) on rectal temperature (RT), heterophil to lymphocyte (H to L) ratio and aberrant behaviours of ostrich chicks transported by road for $4 \mathrm{~h}$ during hot-dry conditions. Twenty ostrich chicks aged 2.5 months, of both sexes and belonging to the Red Neck breed, served as subjects of the study. The chicks were assigned randomly to AA-treated and control groups, consisting of 10 chicks each. The AA-treated group was administered orally with $100 \mathrm{mg} / \mathrm{kg}$ body weight of AA dissolved in $5 \mathrm{~mL}$ of sterile water $30 \mathrm{~min}$ before transportation, whilst the control group was given the equivalent of sterile water only. The thermal load (TL) experienced in the vehicle during transportation fluctuated between $31^{\circ} \mathrm{C}$ and $89^{\circ} \mathrm{C}$, as calculated from the ambient temperature and relative humidity. Transportation induced hyperthermia, lymphopenia, heterophilia and aberrant behaviours of pecking, wing fluffing and panting, which were ameliorated by AA administration. The relationships between the TL, journey duration and physiological variables of $\mathrm{RT}, \mathrm{H}$ to $\mathrm{L}$ ratio and aberrant behaviours recorded during transportation were significantly and positively correlated in the control group. In AA-treated group the relationships were not significantly correlated. In conclusion, the results showed for the first time that AA ameliorated the adverse effects of stress caused by road transportation on the aberrant behaviours, RT and H to L ratio of ostrich chicks during the hot-dry season.

\section{Introduction}

Transportation of animals is known to induce both psychological and physiological stress and stress-induced behavioural changes may result in accompanying major physiological disturbances such as aberrant behaviours, immune-suppression, weight loss and disruption of general homeostasis (Ayo et al. 2009; Minka \& Ayo 2008, 2010; Stewart 1994). It has been established that changes in rectal temperature (RT), heterophil to lymphocyte ratio (H to $\mathrm{L}$ ) and behavioural activities of animals, including birds, are reliable indices of stress and are often used in the development of management strategies aimed at increasing productivity. These changes are important for on-the-spot evaluation of the health status and adaptability of animals to various stress factors, including transportation stress (Ayo, Oladele \& Fayomi 2002; Minka \& Ayo 2007a, 2007b, 2008; Warriss et al. 1993). Very often, behavioural changes are the main signs of distress and the first signs of disease in animals (Ayo et al. 2002).

The high levels of stress suffered by ostriches during road transportation has been sharply criticised by human rights and animal welfare activists because this transportation poses a great risk to both the driver and the birds (Foggin 1992; Hoffman \& Lambrechts 2011; Minka \& Ayo 2008; Wotton \& Hewitt 1999). The lack of adequate recommendations relating solely to the welfare of ostriches during road transportation has aggravated the problem (Ministry for Agriculture, Fisheries and Food 1998; Minka \& Ayo 2008; Piccione et al. 2005). For example, in Nigeria, ostriches are mostly purchased and transported by road from the Northern Guinea Savannah zone, where they are predominantly reared, to new farms, markets, zoos and game reserves in other parts of the country (Ayo \& Minka 2004; Minka 2003; Minka \& Ayo 2007c, 2008). This road transportation covers distances ranging from $200 \mathrm{~km}$ to over $1000 \mathrm{~km}$ and uses vehicles specifically not meant for transportation of ostriches, which demonstrates little consideration for the ostriches' welfare.

In spite of the management procedures toward alleviation of transportation stress in ostriches, which centred solely on vehicle modification and design, reports indicate that the birds still suffer considerable stress during transportation. In addition, the use of neuroleptics and other central nervous depressants resulted in many ostriches developing rhabdomyopathy. Besides, the necessity of using such drugs in transported animals is an indication that those animals' welfare is already poor and compromised (Pfitzer \& Lambrechts 2001). It has, therefore, become necessary to search for safer agents that may alleviate the stresses ostriches suffer during their transportation by road without contravening their welfare and productivity. 
Several studies have successfully employed ascorbic acid (AA), otherwise known as vitamin $\mathrm{C}$, as an ameliorating agent against road transportation stress in livestock, including poultry, because of its antioxidant and inhibitory properties on free radicals. The effects of stress are also apparently reduced, as evidenced by lower cortisol levels (Ayo et al. 2009; Minka \& Ayo 2007b, 2010, 2011). However, such studies in ostriches are currently lacking in the available literature. Therefore, the aims of the present study were to evaluate the effects of a $4 \mathrm{~h}$ road transportation on thermal load (TL), behaviour, RT and immunosuppression of ostrich chicks and to suggest AA as an ameliorating agent in ostrich chicks transported by road during hot-dry conditions.

\section{Materials and methods \\ Thermal environmental and rectal temperature data}

The present study was conducted at the College of Agriculture and Animal Science, Kaduna, which is located at $11^{\circ} 10^{\prime} \mathrm{N}$, $07^{\circ} 38^{\prime} \mathrm{E}$ in the Northern Guinea Savannah zone of Nigeria.

The ambient temperature (AT), relative humidity (RH) and RT were recorded at the sites of the study for seven days before and after transportation, at 07:00, 14:00 and 18:00 each day. These parameters were recorded hourly during the journey. The AT and RH were recorded using a wet-bulb and dry-bulb thermometer (Thermometers Direct Ltd, Aldershot, United Kingdom). The RH was obtained by calculating the depression point from the AT and wet-bulb temperature values. The temperature humidity index (THI), a measure of $\mathrm{TL}$, recorded during the transportation period was obtained from the AT and RH using a THI calculator. The RT was recorded with a digital clinical thermometer (Cocet, Kangfu Medical Equipment Co., Zhejiang, China), inserted about $5 \mathrm{~cm}$ into the rectum via the cloaca for $3 \mathrm{~min}$ until an alarm was heard, indicating the end of the reading.

\section{Experimental birds and measurements}

Twenty apparently healthy, 2.5-month-old farmed ostrich chicks, belonging to the Red Neck breed and of both sexes, served as subjects. The birds weighed $20.7 \mathrm{~kg}$ on average and were obtained from a standard commercial farm, located in Kaduna in the Northern Guinea Savannah zone of Nigeria. The chicks were fed ostrich growers' mash (Feed Master Ltd, Kaduna, Nigeria) with a nutritive value of $2465.0 \mathrm{kcal} / \mathrm{kg}$ metabolised energy, 22\% protein and 12\% fibre. They were given access to water ad libitum in both the farms from which and to which they were transported. One week before transportation, the birds were assigned randomly into AA-treated and control groups, consisting of 10 chicks each. Blood samples were obtained from the ostriches two days prior to transportation in order to obtain base-line (pretransportation) values. On transportation day and $30 \mathrm{~min}$ before loading, the AA-treated group was given $100.0 \mathrm{mg} / \mathrm{kg}$ body weight of AA orally, dissolved in $5 \mathrm{~mL}$ of sterile water, whilst control group was given the equivalent of sterile water only. The $30 \mathrm{~min}$ time lapse from AA administration to loading was allowed for the absorption of the AA before the commencement of the journey. The RT values of the ostriches were recorded $30 \mathrm{~min}$ before and after loading and subsequently every hour of the transportation. During transportation, the behavioural events of individual chicks were recorded continuously, as described by Das, Srivastava and Das (2001) and Minka and Ayo (2010). The behaviour was recorded by four observers inside the vehicle, with each observer recording the on-going behaviour of five chicks in a similar pattern. The number of ostriches that exhibited behavioural events such as panting (hyperventilation), wing fluffing and pecking were recorded whenever they were observed for each hour of the transportation period. Blood samples were obtained immediately on arrival and on the third day after transportation. At each period of blood sampling $5.0 \mathrm{~mL}$ of blood was taken from a wing vein into a heparinised test tube. Monolayer blood films were made from each sample, fixed and stained for differential leucocyte counts (Dacie \& Lewis 1975). Results for heterophils (H) and lymphocytes (L) are presented. The $\mathrm{H}$ to $\mathrm{L}$ ratio was calculated by dividing the value of $\mathrm{H}$ by that of $\mathrm{L}$.

\section{Vehicle loading and transportation procedures}

The ostriches were transported in a modified Bedford van. The floor of the van, which had no holes or gaps, was covered with chopped wood shavings, on top of which was placed a non-slip rubber mat. The windows were covered with grills that permitted the regulation of ventilation. The van was partitioned into 10 compartments with detachable and perforated plastic materials measuring $0.70 \mathrm{~m}$ high. Each compartment housed two ostrich chicks comfortably and with enough space for them to lie down. Although recommendations on stocking density for ostrich chicks during transportation are lacking (Wotton \& Hewitt 1999), in the present study the chicks were stocked at a density of $0.35 \mathrm{~m}^{2}$ per chick. Each partition was fixed in place after loading each ostrich into the vehicle. Similarly, the partitions were detached separately during unloading, starting from the rear of the van and moving to the front.

Transportation was undertaken during the hot-dry period of April. The vehicle travelled for $4 \mathrm{~h}$ - from 08:00 to 12:00 covering a distance of $220 \mathrm{~km}$ on an asphalt road, with an average speed of $50 \mathrm{~km} / \mathrm{h}$. Food and water were withdrawn completely $6 \mathrm{~h}$ before and during the journey period. On arrival, the ostriches were immediately unloaded individually into a pen, where they were fed the same ration given to them before the transportation.

\section{Statistical analysis}

The mean and standard error of different behavioural events were calculated. Data were subjected to the Student's $t$-test, whilst Pearson's correlation analysis was employed in calculating the relationships between the journey periods, AT and behavioural activities. Values of $p<0.05$ were considered significant. 


\section{Ethical considerations}

The handling, loading and transportation of the ostrich chicks were in accordance with national and international guidelines on humane handling and transportation of animals and birds (Farm Animal Welfare Council 2003; Federal Republic of Nigeria 1988; MAFF 1998) and as described by Sales and Smith (1995) and Wotton and Hewitt (1999). The College of Agriculture and Animal Science at the Ahmadu Bello University in Kaduna, Nigeria approved all of the protocols required for the study period, under the permit number VCN-002519.

\section{Potential benefits and hazards}

Both physical and psychological trauma during transportation were anticipated because of the bi-pedal nature of the ostriches, which often leads to traumatic injury, fracture and rabdomyolopathy. Thus, the birds were transported as recommended by the national and international guidelines cited above. To ensure the safety of the birds, the primary author, a Veterinary Surgeon registered with the Veterinary Council of Nigeria, participated fully in the transportation of the birds.

\section{Results}

\section{Thermal conditions and rectal temperature during transportation}

The AT, RH and TL inside the vehicle rose with each hour of the journey, attaining their peak at the fourth hour when the transportation was completed (Table 1). The RT recorded in AA-treated ostrich chicks 30 min after AA administration and just before loading rose $(p<0.05)$ from the mean base-line value of $38.5{ }^{\circ} \mathrm{C} \pm 0.2{ }^{\circ} \mathrm{C}$ to $39.6{ }^{\circ} \mathrm{C} \pm 0.1{ }^{\circ} \mathrm{C}$. Thereafter, the RT of the AA-treated birds declined and fluctuated between the values of $38.5^{\circ} \mathrm{C}$ and $39.0^{\circ} \mathrm{C}$ during the post-loading and transportation periods and did not differ $(p>0.05)$ from the base-line values. In the control group, the RT values recorded after loading and during each hour of the transportation period fluctuated between $38.3^{\circ} \mathrm{C}$ and $40.1{ }^{\circ} \mathrm{C}$, significantly higher than the base-line values and corresponding values obtained in the AA-treated ostriches (Figure 1a).

\section{Aberrant behaviours}

The aberrant behaviours of piloerection (Figure 1b), panting (Figure 1c) and pecking (Figure 1d), recorded in the control ostriches increased $(p<0.05)$ with the journey duration and

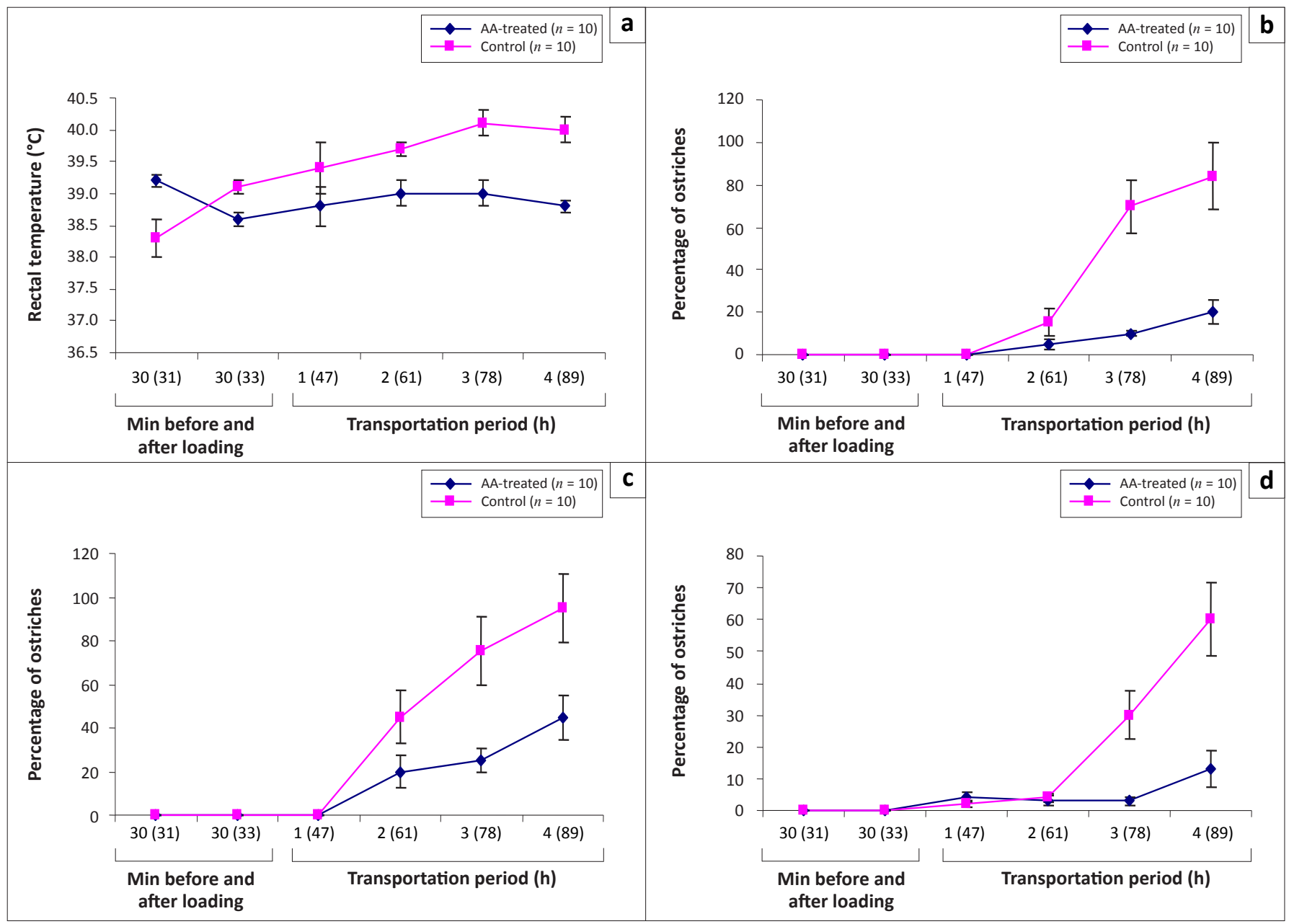

The number in brackets on the $x$-axis represent thermal load.

FIGURE 1: The effects of loading and transportation on, (a) rectal temperature, (b) the exhibition of piloerection behaviour, (c) the exhibition of panting behaviour and (d) the exhibition of pecking behaviour of control and ascorbic acid (AA)-treated ostriches. 
TL; these behaviours manifested apparently during the last hours of the journey when the thermal environment variables were at their peak. In AA-treated ostriches, panting was the only aberrant behaviour that significantly $(p<0.05)$ manifested at the last hour of the journey.

\section{Heterophil to lymphocyte ratio}

The $\mathrm{H}$ to $\mathrm{L}$ ratio of $0.67 \pm 0.30$ recorded in the control chicks immediately after transportation was higher $(p<0.05)$ than the base-line value of $0.33 \pm 0.10$ and the corresponding value of $0.34 \pm 0.10$ recorded in AA-treated chicks after transportation. The $\mathrm{H}$ to $\mathrm{L}$ ratio recorded in the AA-treated group immediately and three days after transportation was not different from the base-line ratio. However, the control chicks had still not returned to the base-line $\mathrm{H}$ to $\mathrm{L}$ ratio three days after transportation (Table 2).

The relationships between the TL, journey duration and physiological variables of $\mathrm{RT}, \mathrm{H}$ to $\mathrm{L}$ ratio and aberrant behaviour recorded during the transportation were significantly and positively $(p<0.001 ; r=0.814)$ correlated in the control group. In AA-treated group the relationships were not significantly correlated (Table 3).

\section{Discussion}

The results obtained in the present study showed that the transportation of ostrich chicks during the hot-dry season is very stressful and poses a risk to the health of the birds, findings which agreed with previous reports (Foggin 1992;
Minka \& Ayo 2007c, 2008; Mitchell et al. 1996). The fact that the ostrich is known to withstand very high environmental temperatures without any consequential adverse effects on its homeostasis (Stewart 1994) suggests that the mean AT value of $35^{\circ} \mathrm{C}$ - recorded during transportation in the present study, and which was far below the temperature $\left(50{ }^{\circ} \mathrm{C}\right)$ at which ostriches begin to experience adverse effects to their homoeostasis - may not be a major cause of transportation stress in the ostriches. This may be true because, unlike mammals and other birds, ostriches have excellent ability to thermoregulate under high AT. However, during transportation, they suffer considerable stress when the AT values are either above or below $20^{\circ} \mathrm{C}$ (Payne 1993; Piccione et al. 2005), which is the recommended thermoneutral zone for ostriches (Skadhauge 1981).

The mean TL value of $51.0{ }^{\circ} \mathrm{C} \pm 7.8{ }^{\circ} \mathrm{C}$ and AT value of $33.6{ }^{\circ} \mathrm{C} \pm 1.1^{\circ} \mathrm{C}$ recorded during the journey were similar to the TL and AT values of $44.0^{\circ} \mathrm{C}$ and $34.0^{\circ} \mathrm{C}$, respectively, obtained during transportation of pullets, and which were reported to induce heat stress in pullets (Minka \& Ayo 2010). The fact that the TL increased with the hour of the day and journey duration suggests that as the journey progressed the effect of TL on the birds also rose. In addition, panting behaviour of the birds increased the $\mathrm{RH}$ in the vehicle, which in turn increased TL. This apparently exacerbated the mechanism of thermoregulation by increasing evaporative heat loss and inducing hyperthermia in the ostriches. Other studies have shown that even at an AT of $18.0{ }^{\circ} \mathrm{C}$ and $\mathrm{RH}$ of $89 \%$ ostriches still suffer transportation stress

TABLE 1: Fluctuations in thermal microenvironment variables inside the vehicle during a four-hour road transportation of ostriches.

\begin{tabular}{|c|c|c|c|c|c|c|c|c|}
\hline \multirow[t]{2}{*}{ Variables } & \multirow{2}{*}{$\begin{array}{l}30 \text { min before } \\
\text { loading }\end{array}$} & \multirow{2}{*}{$\begin{array}{l}30 \text { min after } \\
\text { loading }\end{array}$} & \multicolumn{4}{|c|}{ Transportation period (h) } & \multirow[t]{2}{*}{ Mean } & \multirow[t]{2}{*}{ SEM } \\
\hline & & & 1 & 2 & 3 & 4 & & \\
\hline Ambient temperature $\left({ }^{\circ} \mathrm{C}\right)$ & 28.0 & 28.7 & 32.5 & 35.2 & 37.9 & 39.5 & 33.6 & 1.1 \\
\hline Relative humidity (\%) & 71.0 & 74.0 & 81.0 & 85.0 & 87.0 & 89.0 & 51.0 & 5.6 \\
\hline Thermal load $\left({ }^{\circ} \mathrm{C}\right)$ & 31.0 & 33.0 & 47.0 & 61.0 & 78.0 & 89.0 & 51.0 & 7.8 \\
\hline
\end{tabular}

SEM, standard error of the mean.

TABLE 2: Responses of heterophils and lymphocytes of ascorbic acid-treated $(n=10)$ and control $(n=10)$ ostriches to road transportation stress.

\begin{tabular}{|c|c|c|c|c|c|c|}
\hline \multirow[t]{2}{*}{ Period } & \multicolumn{2}{|c|}{ Heterophil (\%) } & \multicolumn{2}{|c|}{ Lymphocyte (\%) } & \multicolumn{2}{|c|}{ Heterophil to lymphocyte ratio } \\
\hline & AA-treated & Control & AA-treated & Control & AA-treated & Control \\
\hline Pre-transportation & $23.0 \pm 2.4$ & $24.0 \pm 4.5$ & $76.0 \pm 4.7$ & $73.0 \pm 7.7$ & $0.29 \pm 0.10$ & $0.33 \pm 0.10$ \\
\hline Immediately after transportation & $31.0 \pm 4.1$ & $52.0 \pm 8.1^{\text {a }}$ & $78.0 \pm 2.1$ & $84.0 \pm 5.4^{\mathrm{a}}$ & $0.34 \pm 0.10$ & $0.67 \pm 0.30^{\mathrm{a}}$ \\
\hline Three days after transportation & $21.0 \pm 2.7$ & $32.0 \pm 5.5^{b}$ & $74.0 \pm 8.6$ & $81.0 \pm 9.3^{b}$ & $0.28 \pm 0.20$ & $0.40 \pm 0.20^{b}$ \\
\hline
\end{tabular}

AA, ascorbic acid.

a,b, Mean values with different superscript letters in the same column are significantly different $(p<0.05)$.

TABLE 3: Relationships between the hour of the journey, thermal load, rectal temperature and aberrant behaviours in ascorbic acid-treated $(n=10)$ and control $(n=10)$ ostriches during the road transportation period.

\begin{tabular}{llll}
\hline Correlated variables & Treatment group & Hour of the day & Thermal load index $\left({ }^{\circ} \mathrm{C}\right)$ \\
\hline Rectal temperature & AA-treated & $0.448^{\text {ns }}$ & $0.345^{\text {ns }}$ \\
& Control & $0.889^{* * *}$ & $0.921^{* * *}$ \\
Piloerection & AA-treated & $0.348^{\text {ns }}$ & $0.412^{\text {ns }}$ \\
& Control & $0.773^{* *}$ & $0.679^{* *}$ \\
Panting & AA-treated & $0.373^{\text {ns }}$ & $0.541^{*}$ \\
& Control & $0.923^{* * *}$ & $0.899^{* * *}$ \\
Pecking & AA-treated & $0.512^{*}$ & $0.431^{\text {ns }}$ \\
& Control & $0.734^{* *}$ & $0.501^{*}$ \\
\hline
\end{tabular}


(Payne 1993). It appears therefore that other transportation factors such as handling, loading, vehicle vibration, motion, noise and novelty of environment may be the major stress factors affecting the ostrich during transportation, rather than high AT and RH. This requires further investigation.

The base-line values of RT recorded in both treated and control ostriches before transportation did not differ from each other and from the normal range RT values of $38.3{ }^{\circ} \mathrm{C}$ to $39.3{ }^{\circ} \mathrm{C}$ established for ostrich chicks (Skadhauge 1981; Stewart 1994), although the RTs were at their lower limit values. The results were similar to those obtained by Stewart (1994), who showed that ostriches, in contrast to other birds, have an RT below $40.0^{\circ} \mathrm{C}$ and in the range of the eutherian mammals.

The increase in the RT value recorded in AA-treated group 30 min after the administration of AA, but before loading, was within the normal range for the ostrich, but was higher than that of the control, which demonstrated that administration of AA induced RT elevation in the ostriches. This finding supports earlier results that AA exerts a biphasic effect on RT. Firstly, it increases the RT whenever the value is at a lower limit threshold as observed in AA-treated ostriches in the present study. Secondly, it reduces RT values that are at the maximum threshold (Ayo, Minka \& Fayomi 2005; Ayo, Owoyele \& Dzenda 2007).

The increase in RT values recorded in the control group 30 min after handling and loading, but before the transportation, showed that these procedures were stressful to the ostriches. Similar observations were made during the handling, loading and transportation of birds (Minka \& Ayo 2007b, 2011). The increase in RT value at this stage of transportation may not be associated with an increase in TL, but could be explained as a result of physical activity; and also by stressinduced hyperthermia, which is the regulated shift of the thermoregulatory set-point mediated by prostaglandin $\mathrm{E}$ and interleukin 1 and 6 (Kent \& Ewbank 1983; Piccione et al. 2007). Stress-induced hyperthermia is associated with cortisol release and is known to attain peak level within 10 min of administration of a stress factor (Piccione et al. 2007).

The fact that a non-significant $(p<0.05)$ increase in $\mathrm{RT}$ value was recorded post-loading in the AA-treated ostriches suggested, for the first time, that AA alleviated the effects of handling and loading stress on RT of the ostriches. The mechanism of action of AA on the handling and loading stress factors may be caused by the fact that AA is an inhibitory vitaminergic neurotransmitter in the hypothalamus, which plays an important role in thermoregulation by inhibiting cortisol, the chief hormone of stress (Balz 2003; Kannan et al. 2002). This is an important finding because handling and loading of ostriches are the most critical procedures and the major cause of poor welfare (Minka \& Ayo 2007c, 2008).

The progressive increase in RT value during the transportation, especially in the control birds, suggested that transportation itself, apart from the handling and loading procedures, further increased the release of cortisol, which apparently continued to alter RT. The present finding agrees with those of Knowles et al. (1996), Hartung (2003) and Minka and Ayo (2008), who established that the period of transportation of an animal is one of the most traumatic in its life. This is particularly true of ostriches, as they are very social birds and relatively minor changes in their social status may cause severe stress (Stewart 1994). The effects of stress caused by road transportation acting concomitantly with high AT and $\mathrm{RH}$ on the ostriches in the vehicle further aggravated the stressful conditions of the birds.

The insignificant $(p>0.05)$ change in RT value recorded in the AA-treated ostriches, compared to those obtained in the control, further indicated that AA did not only ameliorate the stress imposed by handling and loading, but also the stresses encountered during the actual process of road transportation. Such stresses included vehicle motion, noise, vibration and speed, high AT and RH, long duration of journey, deprivation of food and water, novelty of environment, and confinement. The findings of the present study demonstrated that AA reduced significantly the stress on RT induced by road transportation. The results were similar to those obtained during transportation of ostriches and poultry by road (Minka \& Ayo 2008, 2010). Similar ameliorating effects of AA on the RT of pullets have been documented (Minka \& Ayo 2010, 2011).

The behavioural responses recorded during the third hour of transportation revealed some unusual and aberrant behaviours such as pecking (directed to the ground or to objects), wing fluffing (piloerection) and panting (polypnoea), especially in the control ostriches. The manifestations of these behaviours suggest that the ostriches were stressed and the level of stress increased with the duration of the journey and TL. Although ostriches are known to have a wide range of thermoregulatory set points, it has been reported that ostrich chicks are affected severely by hot weather (Minka \& Ayo 2007c; Reiner, Seitz \& Dzapo 1996; Stewart 1994), as confirmed by the present study. The aberrant behaviours of polypnoea and piloerection were responses of the birds to increased demand in oxygen and heat dissipation brought about by the high AT and RH recorded in the vehicle during the transportation. Because ostriches, like other birds, have no sweat glands, the only means available for cooling is evaporation via polypnoea and piloerection by exposing the bare skin on their thorax and upper legs to enhanced convection and radiation losses. Similar observations on the behaviours of ostriches exposed to different thermal conditions have also been reported (Samson 1996).

Although the vehicle cabin was well ventilated, the air entering the vehicle was very hot and did not exert any cooling effect on the birds. This is characteristic of the hot-dry season in the zone of study. The present result showed that ostriches began to pant when the TL value was $40{ }^{\circ} \mathrm{C}$. The result obtained in AA-treated birds demonstrated that AA 
has reduced the effect of TL on the birds and facilitated the physiological mechanism of thermoregulation. It has been established that AA decreases heat load through reduction in heat production or increasing heat loss by enhancing thermal exchange between the body and the environment (Chang et al. 1993; Minka \& Ayo 2010; Tauler et al. 2003). Similarly, AA enhanced the adaptability of poultry and animals to environmental stress (McKee \& Harrison 1995; Minka \& Ayo 2010). The mechanism of action of AA in reducing heat stress may also be through the detoxification of reactive oxygen species known to be in abundance in the body during stressful conditions (Minka \& Ayo 2007b; Tauler et al. 2003).

The intense pecking behaviour exhibited by the ostriches in the control group may be associated with frustration, hunger and metabolic stress caused by transportation procedures, which are tasking and completely novel to the birds (Foggin 1992). The fact that pecking behaviour was less manifested in AA-treated birds suggested that AA reduced the bird's frustration. AA is known to be the first vitaminergetic neurotransmitter and it plays a significant role in inhibiting cortisol, the chief hormone of stress, and the limbic region involved in the elicitation of fear and frustration (Balz 2003; Karanth et al. 2000).

The significant $(p<0.05)$ increase in $\mathrm{H}$ to $\mathrm{L}$ ratio recorded in the control ostriches post-transportation indicated that the immune system of the birds was compromised as a result of transportation up to the third day of the post-transportation period. The $\mathrm{H}$ to $\mathrm{L}$ ratio has been used as the most common reliable index of stress measurement from blood analysis (Kannan et al. 2002; Minka \& Ayo 2007b, 2011). A similar effect of transportation stress on $\mathrm{H}$ to $\mathrm{L}$ ratio was reported in poultry, including ostriches (Minka \& Ayo 2007b, 2008, 2011) and the increase in $H$ to $L$ ratio has been reported to reflect the effects of elevated corticosteroids in the circulation induced by stress (Kannan et al. 2002; Schalm, Jain \& Carroll 1975). The insignificant change in $\mathrm{H}$ to $\mathrm{L}$ ratio obtained in AAtreated ostriches post-loading was an indication of reduced physiological stress. The result showed, for the first time, that AA alleviated the stresses induced by both the transportation proper and the post-transportation procedures on the lymphocytes and heterophils of the ostriches. AA has been reported to be a chain-breaking antioxidant, involved in the prevention and restriction of free-radical chain formation and propagation. Consequently, AA enhances the immune status of the ostriches by protecting the blood cells, including heterophils and lymphocytes, from oxidative damage induced by free radicals and cortisol (Alok et al. 2003; Elsayed, Farghaly \& Abu-Taleb 2008; Tauler et al. 2003). Although there are no recommended doses for $\mathrm{AA}$ as an antioxidant in ostriches, it has been shown that it ameliorates heat stress in ostriches in supplementation, at a dose of $250 \mathrm{mg} / \mathrm{kg}$ of feed (Elsayed et al. 2008).

\section{Conclusion}

The results of the present study have demonstrated for the first time that AA administration prior to the commencement of road transportation was beneficial to ostrich chicks and may be used to improve the bird's welfare and make their transportation more economically viable. For example, AA ameliorated the adverse effects of stress caused by road transportation on the behaviour, $\mathrm{RT}$ and $\mathrm{H}$ to $\mathrm{L}$ ratio of ostrich chicks. It also enhanced the homeostatic mechanisms of behavioural, thermoregulatory and cellular immune responses of ostrich chicks to the stressful conditions imposed by road transportation during the hot-dry season. AA is readily available, cheap, safe and easy to administer in ostrich chicks, making it an ideal supplement for use during transportation.

\section{Acknowledgements}

The authors are grateful to all laboratory staff of the College of Agriculture and Animal Science at the Ahmadu Bello University, Kaduna for their technical assistance.

\section{Competing interests}

The authors declare that they have no financial or personal relationship(s) which may have inappropriately influenced them in writing this paper.

\section{Authors' contributions}

M.N.S. (Ahmadu Bello University, Kaduna) was the project leader. He supervised the transportation, provided logistics, collected and prepared all samples and data. He also provided an initial draft of the manuscript, whilst A.J.O. (Ahmadu Bello University, Zaria) designed the project, statistically analysed the results and wrote the manuscript to standard.

\section{References}

Alok, K.B., Amrittal, M., Dipanjan, C. \& Sajal, C., 2003, 'Oxidants, antioxidants and physical exercise', Molecular and Cellular Biochemistry 253, 307-312. http:// dx.doi.org/10.1023/A:1026032404105, PMid:14619981

Ayo, J.O. \& Minka, N.S., 2004, 'Effect of six-hour road transportation on some physiological parameters in ostriches', Proceedings of the 29th Annual Conference of Nigerian Society for Animal Production, Sokoto, Nigeria, 21-25 March, pp. 5861 , Nigerian Society for Animal Production Publishers, Abuja.

Ayo, J.O., Minka, N.S. \& Fayomi, A., 2005, 'Effects of ascorbic acid on rectal temperature of pullets transported by road during the hot-dry season', Tropical Journal of Animal Science 8, 43-48.

Ayo, J.O., Minka, N.S., Sackey, A.K.B. \& Adelaye, A.B., 2009, 'Responses of serum electrolytes of goats to twelve hours of road transportation during the hotdry season in Nigeria, and the effect of pretreatment with ascorbic acid' Onderstepoort Journal of Veterinary Research 78, 409-418.

Ayo, J.O., Oladele, S.B. \& Fayomi, A., 2002, 'Behavioural reactions of cattle to stress situations: A review', Journal of Agricultural Technology 8, 15-20.

Ayo, J.O., Owoyele, O.O. \& Dzenda, T., 2007, 'Effects of ascorbic acid on diurnal variations in rectal temperature of Brown Nera pullets during the harmattan season', International Journal of Poultry Science 6, 612-616. http://dx.doi. org/10.3923/ijps.2007.612.616

Balz, F., 2003, 'Vitamin C intake', Nutritional Disease 14, 1-18.

Chang, K.C., Chong, W.S., Sohn, D., Kwon, B.H., Lee, I.J., Kim, C.Y. et al., 1993 'Endothelial potentiation of relaxation response to ascorbic acid in rat and guinea 'Endothelial potentiation of relaxation respon
pig thocic aorta', Life Science 52, 37-42.

Dacie, J.U. \& Lewis, S.M., 1975, Practical haematology, 5th edn., Churchill Livingstone, Edinburgh.

Das, K.S., Srivastava, B.B. \& Das, N., 2001, 'Standing orientation and behaviour of goats during short-haul road transportation', Small Ruminant Research 41(1), 91-94. http://dx.doi.org/10.1016/S0921-4488(01)00187-0

Elsayed, M.A., Farghaly, H.A.M. \& Abu-Taleb, A.M., 2008, 'Effect of vitamin C supplementation on some physiological parameters of ostrich exposed to early heat stress of temperature', Applied Life Science 40(4S2), 1503-1513.

Farm Animal Welfare Council, 2003, Farm animal at slaughter or killing: Part 1, Defra Publications, London. 
Federal Republic of Nigeria, 1988, Animal Disease (Control) Decree (Act No. 10 of 1988), Government Gazette Feb, A477-501, Government Printers, Lagos.

Foggin, C.M., 1992, 'Veterinary problems of ostriches', in M.G. Hallam (ed.), The Topaz introduction to practical ostrich farming, pp. 61-96, Superior Print, Harare.

Hartung, J., 2003, 'Effects of transport on health of farm animals', Veterinary Research Communication 27, 525-527. http://dx.doi.org/10.1023 B:VERC.0000014212.81294.78, PMid:14535462

Hoffman, L.C. \& Lambrechts, H., 2011, 'Bird handling, transportation, lairage, and slaughter: Implications for bird welfare and meat quality', Animal Welfare 11 195-235. http://dx.doi.org/10.1007/978-3-642-19297-5_10

Kannan, G., Terril, T.H., Kouokou, B., Gelaye, S. \& Amoah, E.A., 2002, 'Simulated preslaughter holding and isolation effects on stress responses and liveweight shrinkage in meat goats', Journal of Animal Science 80, 1771-1780. PMid:12162644

Karanth, S., Yu, W.H. Walczewska, A., Mastronardi, C. \& McCann, SM., 2000, 'Ascorbic acid acts as an inhibitory transmitter in the hypothalamus to inhibit stimulated lutenizing hormone-releasing hormone release by scavenging nitric oxide', lutenizing hormone-releasing hormone release by scavenging nitric oxide',
Proceedings of the Academy of Sciences of the United State of America 97, 1891Proceedir

Kent, J.E. \& Ewbank, R., 1983, 'The effect of road transportation on the constituent and behaviour of calves: 1. Six months old', British Veterinary Journal 139, 228235.

Knowles, T.G., Ball R.C., Warriss, P.D. \& Edwards, J.E., 1996, 'A survey to investigate potential dehydration in slaughtered broiler chickens', British Veterinary Journa 152, 307-314. http://dx.doi.org/10.1016/S0007-1935(96)80102-3

Ministry for Agriculture, Fisheries and Food, 1998, Guidance on the welfare of animals (transport) Order 1997, No. PB 3766, Her Majesty's Stationery Office, London.

McKee, J.S. \& Harrison, P., 1995, 'Effects of supplemental ascorbic acid on the performance of broilers chickens exposed to multiple stressors', Poultry Science 74, 1772-1785. PMid:8614686

Minka, N.S., 2003, 'Evaluation of the performance of ostrich chicks in northern Nigeria', Tropical Journal of Animal Science 6, 69-73.

Minka, N.S. \& Ayo, J.O., 2007a, 'Effects of loading behaviour and road transport stress on traumatic injuries in cattle transported by road during the hot-dry season', Livestock Science 107, 91-95. http://dx.doi.org/10.1016/j.livsci.2006.10.013

Minka, N.S. \& Ayo, J.O., 2007b, 'Haematology and behaviour of pullets transported by road and administered with ascorbic acid during the hot-dry season', Research in Veterinary Science 85(2), 389-393. http://dx.doi.org/10.1016/j.rvsc.2007.11.009, PMid:18179807

Minka, N.S. \& Ayo, J.O., 2007c, 'Road transportation effect on rectal temperature, respiration and heart rates of ostrich (Struthio camelus) chicks', Veterinarski Arhiv $77,39-46$.

Minka, N.S. \& Ayo, J.O., 2008, 'Assessment of the stresses imposed on adult ostriches (Struthio camelus) during handling, loading, transportation and unloading', Veterinary Record 162, 846-851. http://dx.doi.org/10.1136/vr.162.26.846, PMid:18587061
Minka, N.S. \& Ayo, J.O., 2010, 'Behavioural and rectal temperature responses of Black Harco pullets administered vitamin $\mathrm{C}$ and $\mathrm{E}$ and transported by road during the hot-dry season', Journal of Veterinary Behavior and Clinical Applications and hes-dry season', Journal of Veterinary Behavior and 134-144. http://dx.doi.org/10.1016/j.jveb.2009.12.022
Research

Minka, N.S. \& Ayo, J.O., 2011, 'Modulating role of vitamins C and E against transportinduce stress in pullets during the hot-dry conditions', ISRN Veterinary Science 2011, Art. \#497138, 7 pages. http://dx.doi.org/10.5402/2011/497138

Mitchell, M.A., Kettlewell, P.J., Sandercock, R. \& Spackman, D.A., 1996, ‘Physiological stress in ostriches during road transportation', in D.C. Deeming (ed.), Improving our understanding of ratites in farming environment, Ratite Conference proceedings, 27-29 March, University of Manchester, UK, pp. 79-80.

Payne, H., 1993, 'Welfare of ostriches and other ratites during transport', State Veterinary Journal 3(4), 8-12.

Pfitzer, S. \& Lambrechts, H., 2001, 'The use of haloperidol during transport of adult ostriches', Journal of the South African Veterinary Association 72(1), 2-3. PMid:11563712

Piccione, G., Coste, A., Gurlice, E. \& Caola, G., 2005, 'Preliminary investigation into thermal stress during diurnal road transportation of young ostriches', Archiv für Tierzucht 48, 194-200.

Piccione, G., Fazio, F., Giannett, C., Assenza, A. \& Caola, G., 2007, 'Oxidative stress in thoroughbreds during official 1800-metre races', Veterinarski Arhiv 77(3), 219227.

Reiner, G., Seitz, K. \& Dzapo, V., 1996, 'A survey of farming environment and ostrich behaviour', in D.C. Deeming (ed.), Improving our understanding of ratites in
farming environment, Ratite Conference proceedings, 27-29 March, University of farming environment, Ratite
Manchester, UK, pp. 52-56.

Sales, J. \& Smith, W.A., 1995, Incubation and management of ostrich and ostrich products, University Printers, Stellenbosch.

Samson, J., 1996, 'Behavioural problems in farmed ostriches in Canada', Canadian Veterinary Journal 37, 412-414. PMid:8809393, PMCid:1576451

Schalm, O.W., Jain, N.C. \& Carroll, E.J., 1975, Veterinary haematology, 3rd edn., Lea and Febiger, Philadelphia.

Skadhauge, E., 1981, Osmoregulation in birds, Springer-Verlag, Berlin.

Stewart, J.S., 1994, 'Ostrich behaviour and behavioural problems', Proceedings of the Annual Conference of Avian Veterinarians, 28-30 September, Reno, USA, pp. 104-109, Association of Avian Veterinarians, Denver.

Tauler, P., Aguilo, A., Gimeno, I., Fuentespina, E., Tur, J.A. \& Pons, A., 2003, 'Influence of vitamin $C$ diet supplementation on endogenous antioxidant defense during exhaustive exercise', European Journal of Physiology 446, 658-664.

Warriss, P.D., Kestin, S.C., Brown, S.N., Knowles, T.G., Wilkins, L.J., Edwards, J.E. et al., 1993, 'The depletion of glycogen stress and indices of dehydration in transported broilers', Veterinary Record 149, 391-398.

Wotton, S.B. \& Hewitt, L., 1999, 'Transportaton of ostriches - A review', Veterinary Record 145, 725-731. PMid:10972110 